\title{
La Sanidad en la Base Antártica del E.T. «Gabriel de Castilla"
}

\author{
De Diego Lousa F. ${ }^{1}$, Rodrigo Arrastio CF. ${ }^{2}$, Pérez Azuara F. ${ }^{3}$, Sánchez Martín de la Peña R. ${ }^{4}$
}

Sanid. mil. 2011; 67 (2): 115-126; ISSN: 1887-8571

\section{RESUMEN:}

En marzo de 2007, dio comienzo el Año Polar Internacional 2007-2008 (IPY), que se desarrolló durante 2 años hasta marzo de 2009, para abarcar temporadas completas en el Ártico y en la Antártida. Es un acontecimiento de carácter científico y a escala mundial, que tiene carácter conmemorativo. Su celebración coincide con el 125 aniversario del Primer Año Polar Internacional (1887-1888), el 75 Aniversario del Segundo Año Polar Internacional (1932-1933) y el 50 Aniversario del Año Geofísico Internacional (1957-1958), que condujo al establecimiento del SCAR y del Tratado Antártico. El IPY 2007-2009 está promovido por el Internacional Council for Science (ICSU) y la World Meteorological Organization (WMO). España es la primera vez que ha participado activamente en este acontecimiento, haciéndolo con la primera campaña Ártica del BIO Hespérides, y con las 2 bases antárticas operativas. Para la base Antártica del Ejército de Tierra «Gabriel de Castilla», el año 2008 es especial ya que, a la celebración del Año Polar Internacional, se une la conmemoración del 20 aniversario de la presencia española en la Isla Decepción. Fue en el año 1988 cuando se instaló un primer refugio, pero no fue hasta el año 1998, cuando tuvo consideración de Base Antártica. Este artículo tiene como finalidad la descripción de las áreas de Sanidad y de Medio Ambiente, tal y como se denominan en la estructura de la Campaña Antártica del Ejército de Tierra, o áreas cuya responsabilidad corresponden a Oficiales del Cuerpo Militar de Sanidad; también conmemorar esta fecha tan señalada, y a las personas que han participado en las distintas campañas antárticas.

KEY WORDS: Base Antártica «Gabriel de Castilla», Año Polar Internacional, Ejército de Tierra, Comité Polar Español.

\section{The Medical Service in the Army's Antarctic Base «Gabriel de Castilla»}

\section{SUMMARY:}

In March 2007 began the International Polar Year 2007-2008 (IPY) that lasted two years until March 2009 to span complete seasons in the Arctic and the Antarctic. It is a scientific event on a global scale with a commemorative character. Its celebration coincides with the 125 th Anniversary of the First International Polar Year (1887-1888), the 75th Anniversary of the Second International Polar Year (1932-1933) and the 50th Anniversary of the International Geophysical Year (1957-1958) which led to the establishment of the SCAR and the Antarctic Treaty. The IPY 2007-2009 is promoted by the International Council for Science (ICSU) and the World Meteorological Organization (WMO). Spain has actively participated, for the first time, in this event with the first Arctic Campaign of the BIO «Hespérides» and the two operational Antarctic bases. For the Army's Antarctic base «Gabriel de Castilla» the year 2008 is special as it combines the celebration of the IPY with the commemoration of the 20th anniversary of the Spanish presence in Deception Island. It was in 1988 when the first shelter was established, although it was not considered an Antarctic Base until 1998. The aim of this article is to present the Environment and Health fields, as they are called in the structure of the Army Antarctic Campaign and which are the responsibility of Medical Service officers, as well as commemorate this significant date and remember the participants in the different Antarctic Campaigns.

KEY WORDS: Antarctic Base «Gabriel de Castilla», International Polar Year, Army, Spanish Polar Committee.

\section{INTRODUCCIÓN}

El Continente Antártico siempre ha despertado una gran expectación en todo el mundo, tanto de tipo científico, como económico o estratégico, y aunque algunos científicos españoles, individualmente o a través de conciertos con expediciones de otros países,

\footnotetext{
${ }^{1}$ Tcol. Médico. Escuela Militar de Montaña y Operaciones Especiales. Asesor médico Comité Polar Español. Jaca (Huesca). España.

${ }^{2}$ Cap. Médico. Unidad Médica Aérea de Apoyo al Despliegue. Zaragoza. España.

${ }^{3}$ Tte. Veterinario. Unidad Logística $n^{\circ} 23$. Ceuta. España.

${ }^{4}$ Tte. Enfermero. Bandera de Infantería Ligera Paracaidista «Ortiz de Zárate» III. Jabalí Nuevo (Murcia). España.
}

Dirección para correspondencia: Capitán Médico D. Carlos F. Rodrigo Arrastio. UMAAD-Zaragoza. Base Aérea de Zaragoza. Ctra. Del Aeropuerto s/n. 50071-Zaragoza. Teléfono: 976708785 / 8285785. crodarr@et.mde.es

Recibido: 21 de junio de 2010

Aceptado: 2 de febrero de 2011 ya habían realizado estudios en la Antártida, como el Dr. Ballester, biólogo marino que participó en 1966 en una expedición belga, o el Dr. Ortiz, vulcanólogo, que participaría a partir de 1986 en campañas argentinas en la isla Decepción, no fue hasta el año 1982 que España firma su adhesión al Tratado Antártico y con ello comienzan las distintas expediciones organizadas por nuestro país.

A finales de ese mismo año la goleta «Idus de Marzo» parte de Candás (Asturias), para convertirse en la primera expedición científica española al continente blanco (1982-83) como cuenta en el libro de Fernando Rodríguez Jiménez «Así se hizo Idus de Marzo». Entre los miembros de la misión, destacaron los armadores Santiago Cañedo (y capitán) y Juan Babé, el biólogo Alberto Vizcaíno, y el también biólogo Juan Antonio Martín. Esta expedición organizada por una asociación privada (Asociación de España en la Antártida), y patrocinada por Guillermo Cryns, precedió a la que se realizó en el año 1986-87, patrocinada por la Secretaría General de Pesca Marítima, y en la que participó el Instituto Español de Oceanografía, 


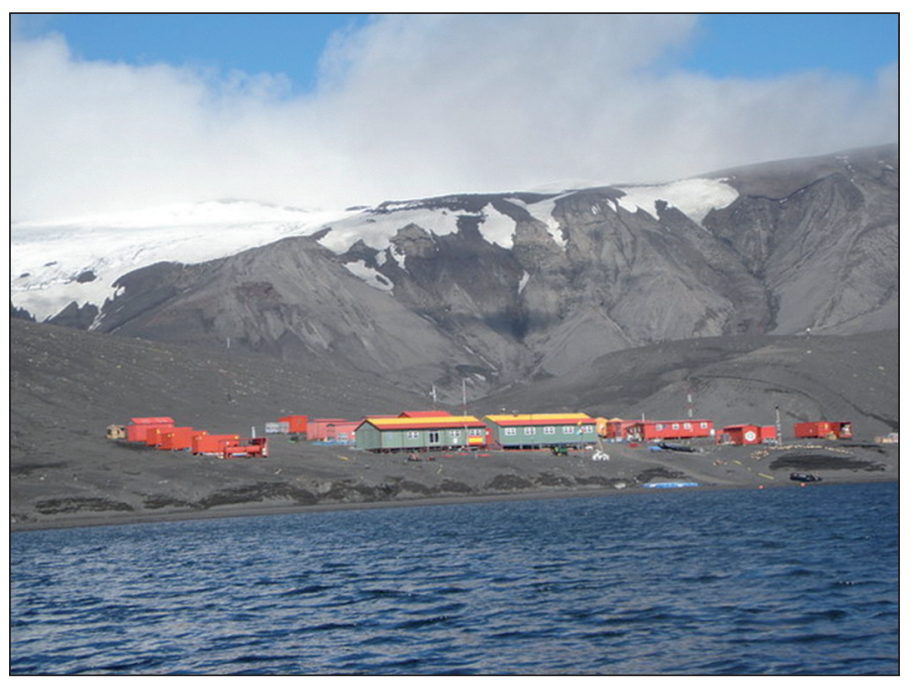

Figura 1. Base Gabriel de Castilla 2008/09.

formando una expedición científico-pesquera, para la que se emplearon dos buques, el «Nuevo Alcocero» (como buque explorador pesquero) y el «Pescapuerta IV» (como buque investigador). Este equipo realizó estudios sobre biología marina, meteorología, biología y geología ${ }^{1}$.

En enero de 1988, el Centro Superior de Investigaciones Científicas (CSIC), instala en la península de Hurd, bahía sur de la isla Livingston, la Base Juan Carlos I, gracias a un acuerdo con el Comité Polar de Polonia para el traslado de personal y material para su instalación. Ese mismo año el Ministerio de Defensa realiza su primera expedición científica a bordo del buque chileno «Río Baker» y el 20 de diciembre de 1988, el buque «Las Palmas» culmina su primera travesía a la base Juan Carlos I, en la isla Livingston y se convierte en la plataforma logística y científica de apoyo a las bases españolas en la Antártida².

Finalmente, a finales del año 1989 se instala en la isla Decepción el refugio militar «Gabriel de Castilla», donde trabaja tanto personal civil como militar, pero no fue hasta el año 1998 que tomó consideración de base antártica. En la campaña 2007/08 y 2008/09 se ha realizado una gran ampliación con la incorporación de un nuevo módulo de vida así como de varios contenedores para el almacenamiento de material ${ }^{3}$.

Este artículo tiene como objetivo dar a conocer la función del personal de sanidad en una campaña antártica, los medios que dispone la Base Gabriel de Castilla para realizar nuestro trabajo, y también servir de reconocimiento a todo el personal militar que ha pasado por sus instalaciones, en especial al del Cuerpo Militar de Sanidad que en estos 20 años ha dado apoyo a personal civil y militar en un entorno único como es la Isla Decepción.

\section{FASES DE LA CAMPÃ̃A ANTÁRTICA}

La XXI Campaña Antártica del Ejército de Tierra (NOV2007MAR2008) estaba compuesta por 11 militares, 2 de ellos del Cuerpo Militar de Sanidad, un Oficial Médico y un Oficial Veterinario. Esa campaña tenía varias circunstancias especiales ya que durante el año 2008 se cumplía el 20 aniversario de la presencia española en la Antártida, y además se celebraba el $4^{\circ}$ Año Polar Internacional (2007$2009)^{4}$, que era el primero en su historia en el que participaba España.

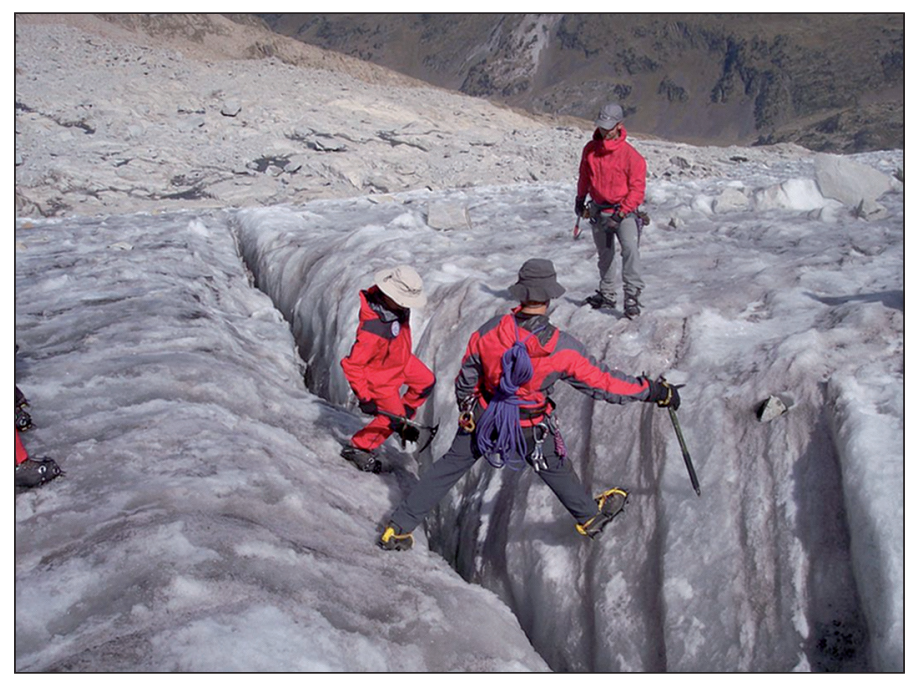

Figura 2. Fase de montaña. Glaciar del Aneto. Huesca 2007.

La preparación de una Campaña Antártica es bastante compleja y precisa de una serie de fases, cada una de ellas con sus características específicas. Hay que puntualizar que estas fases son las que se desarrollan en el Ejército de Tierra, ya que la Armada tiene sus propios mecanismos para la designación del personal así como para la preparación previa de la travesía.

\section{Fase de selección}

La fase de selección se inicia a principios de año, con la designación del jefe de la campaña que es el que diseña y desarrolla el programa de entrevistas y selección del personal, las actividades previas al despliegue y es el director y máximo responsable de todas las actividades y acciones a realizar en la base.

\section{Fase de preparación}

Esta fase se desarrolla en Territorio Nacional e incluye varias subfases. Todo el personal civil y militar que es designado para participar en la campaña debe realizar un reconocimiento médico

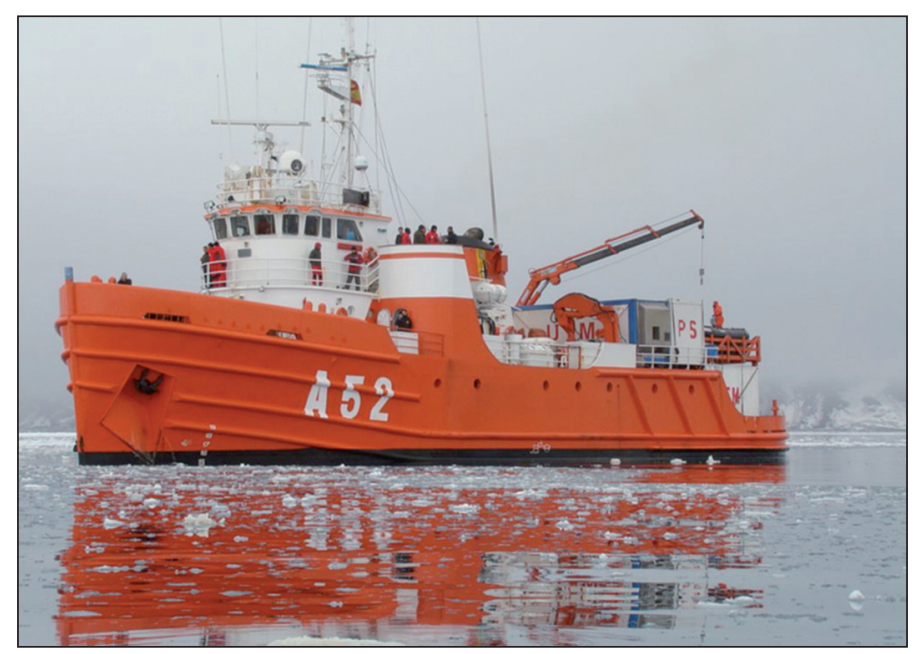

Figura 3. BIO «Las Palmas». 


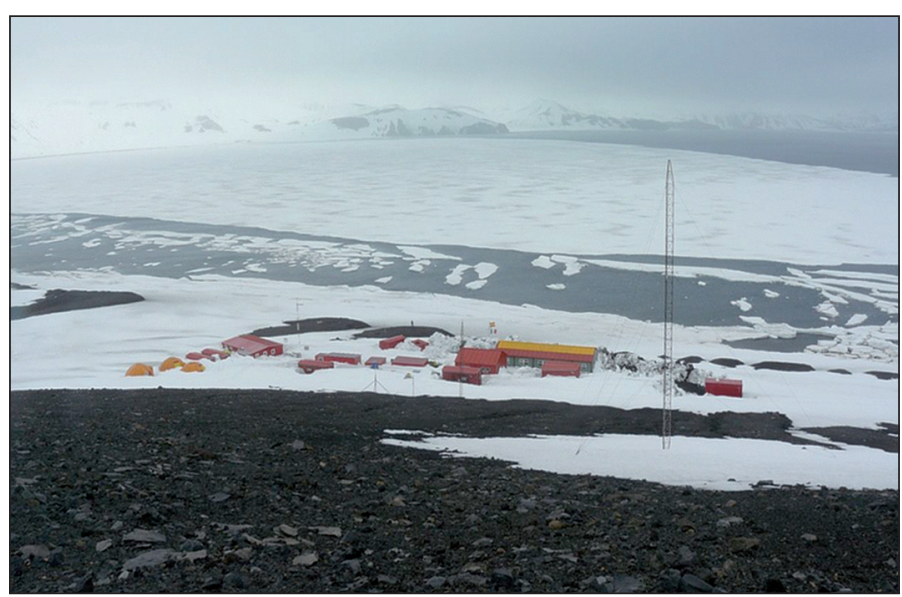

Figura 4. «Banquisa» en la Bahía Decepción.

específico, superar la realización de varios cursos de capacitación antártica y preparar la planificación, adquisición y carga de todo el material necesario para el correcto desarrollo de cada área de responsabilidad en la fase de activación.

\section{a) Reconocimiento médico}

En el año 2007, el personal militar del Ejército de Tierra, como de la Armada (Buque Las Palmas y Hespérides) realizó dicho reconocimiento en el Hospital Básico de la Defensa de Cartagena, mientras que el personal civil, lo hizo en distintos centros sanitarios públicos y privados. Actualmente, el personal militar, y el personal civil que lo solicita, realiza este reconocimiento en el Hospital General de la Defensa de Zaragoza, y en el Hospital Central de la Defensa «Gómez Ulla» de Madrid. El personal que supera este reconocimiento es designado miembro de la Campaña Antártica, e incluye los siguientes parámetros:

- Analítica de sangre: hemograma, bioquímica, VIH.

- Analítica de orina: Básico de orina y sedimento.

- Rx tórax. AP y LAT.

- Rec. Cardiológico. ECG 12 Derivaciones.

- Rec. Odontológico.

- Rec. ORL

- Rec. Psicológico: Entrevista.

- Rec. Digestivo. Ecografía abdominal.

- Rec. Oftalmológico.

- Rec. Médico General: Anamnesis. Valoración clínica general.

Este reconocimiento médico es fundamental a la hora de verificar el estado previo del personal que va a acudir a una zona que está tan alejada de todo centro hospitalario, de conocer cualquier aspecto

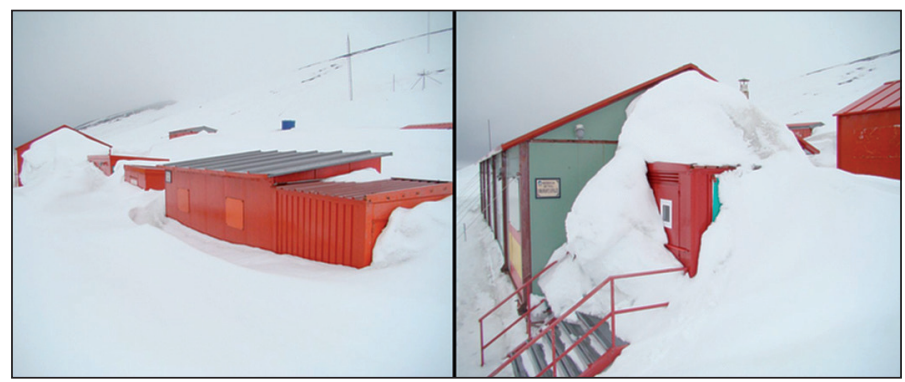

Figura 5. Apertura Base «Gabriel de Castilla» 2007. de la salud de los científicos que acuden a la misma a investigar y rechazar al personal que no se considera que está en condiciones de realizar la campaña.

Junto a este reconocimiento, se realiza el control del estado vacunal del personal, específicamente el módulo básico (Difteria-Tétanos, Hepatitis B, Tifus), aunque, en nuestra campaña, se incluyeron las vacunas de gripe estacional y fiebre amarilla, por la aparición de varios casos en ciertas zonas de Argentina.

\section{b) Cursos de capacitación antártica}

La situación de la isla Decepción, su aislamiento y las distintas actividades que se han de llevar a cabo allí, hacen necesario que el personal comisionado esté preparado para realizar distintas tareas, muchas de ellas muy diferentes a las que realiza habitualmente. Por ello fue necesario prepararnos con una serie de cursos para adquirir ciertas capacidades que nos hiciera polivalentes. Los cursos que realizamos fueron:

- Fase de Navegación e introducción antártica. Teórico-Práctica, realizada en el CBA de Cartagena.

- Fase de Montaña. Curso práctico, que incluyó la ascensión al glaciar del pico Aneto, prácticas en hielo y conducción de vehículos tipo quad en zonas de montaña.

- Título de la Federación Andaluza de Motonáutica. Capacitación para el manejo de embarcaciones de menos de 7 metros, que se realizó en Cádiz.

- Fase de Capacitación en materia medio ambiental. Teórica impartida por el Oficial Veterinario.

- Capacitación en Soporte Vital Básico. Teórico-Práctica impartida por el Oficial Médico.

\section{c) Adquisición, planificación, preparación y carga del material}

El personal responsable de cada área debe planificar, preparar y proponer la adquisición del material necesario para la siguiente campaña tras la reunión que se mantiene con el personal de cada área de la campaña anterior. Las áreas en las que se estructura el personal son: Alimentación, Motores, Instalaciones, Comunicaciones, Navegación, Medio Ambiente y Medicina. Todo el material se centralizó en el depósito antártico de la Agrupación de Apoyo Logístico de Zaragoza (AALOG 41) momento en que se realizó la carga en contenedores y se envío a Ushuaia (Argentina).

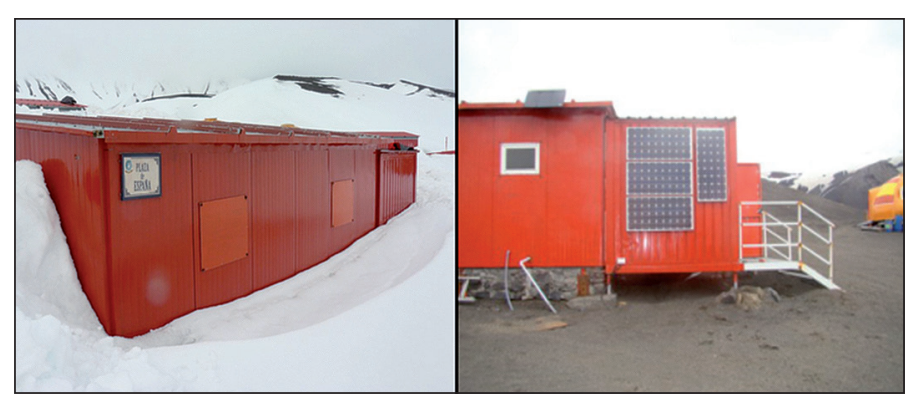

Figura 6. Enfermería «Cap. Médico Ramón y Cajal». Sistema de placas solares. 


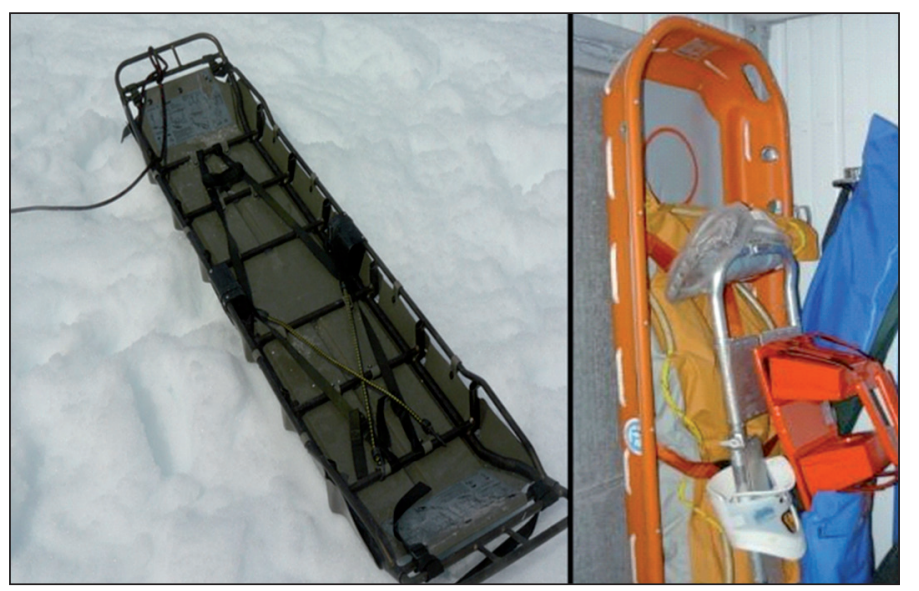

Figura 7. Camilla UT 2000. Material de rescate e inmovilización.

\section{d) Otras actividades}

Una parte importante de la fase de preparación es la divulgación y presentación al público en general, y a los medios de comunicación en particular, la campaña. La presentación del año 2007 se realizó en el Oceanográfic de Valencia. También es fundamental la reunión previa con el Comité Polar Español, en Madrid, en el que se toma contacto con los proyectos y el personal civil que va a acudir a la campaña.

\section{Fase de activación o ejecución}

La fase de activación comenzó el 13 de noviembre de 2007, fecha en que partimos desde el aeropuerto de Madrid-Barajas a la ciudad de Buenos Aires, donde realizamos varias reuniones previas con diversos organismos civiles y militares, destacando la visita al Comando Antártico del Ejército Argentino, a la Dirección Nacional Antártica (DNA) y a la Agregaduría Militar Española en Buenos Aires. Tras este período de reuniones, volamos a Ushuaia, en el cono sur de Argentina, donde realizamos la carga del material al $\mathrm{BIO}$ «Las Palmas» de la Armada que había partido de España previamente. (BIO: buque invest. oceanográfica).

Este buque, auténtico cordón umbilical con el continente americano, da apoyo logístico a las bases antárticas españolas: Base Juan Carlos I, y Base Gabriel de Castilla. Entre su dotación, cuenta con un Oficial Médico y un Oficial Enfermero y posee una pequeña enfermería de entidad tipo role 1, así como material necesario para realizar funciones de atención primaria y aplicar medidas de soporte vital básico y avanzado. La duración del trayecto para cubrir los $1.000 \mathrm{kms}$. entre Ushuaia y la Isla Decepción es de 3 días.

La apertura de la Base «Gabriel de Castilla» en el año 2007 tuvo la particularidad y dificultad de encontrarnos la misma, literalmente cubierta de nieve, así como la bahía con una gran placa de hielo («banquisa») que impedía que se acercara el buque «Las Palmas» hasta el punto de varada. Eso hizo que tuviéramos que desembarcar personal y material a unos 600 metros de distancia de la base. Una vez allí se desarrollaron durante 3 meses las actividades científicas y militares que se habían preparado y planificado desde España. El cierre de la base tuvo lugar el 6 de marzo de 2008 .

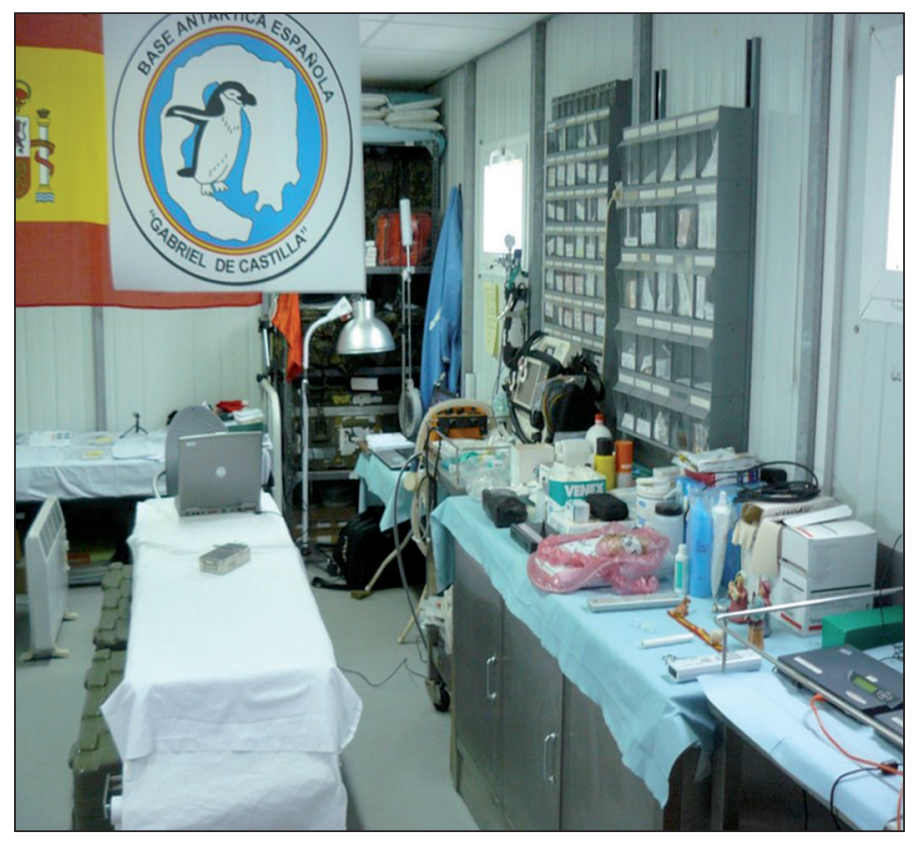

Figura 8. Área de asistencia primaria y curas.

\section{Fase de desactivacion}

El 25 de marzo de 2008, regresamos a Territorio Nacional, tras haber concluido los trabajos de apoyo al personal científico y de mantenimiento de la base. Una vez acabada la fase de activación, queda el trabajo de realizar los correspondientes informes de final de campaña, así como realizar las distintas propuestas de cada área de trabajo para el personal de la siguiente campaña. También se recepciona el material que se ha repatriado de la base por distintos motivos, la mayoría de ellos por reparación o mantenimiento. A mediados del mes de mayo se realizó el relevo a la siguiente campaña en la Jefatura Logística Terrestre de Zaragoza.

\section{ÁREA DE MEDICINA}

El área de medicina es responsabilidad de un Oficial del Cuerpo Militar de Sanidad, especialidad fundamental medicina. La selección del mismo se realiza a través de una entrevista en la que

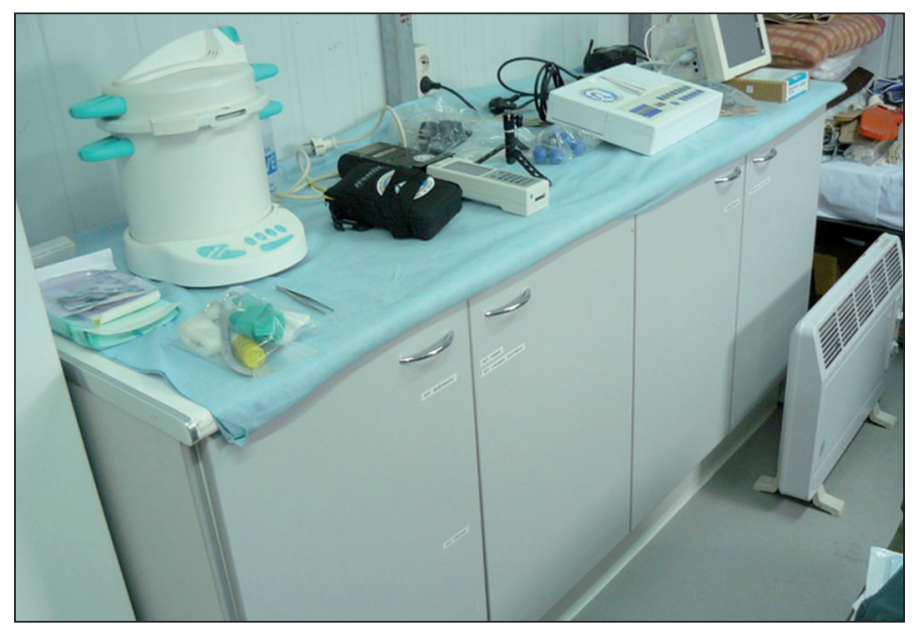

Figura 9. Área de diagnóstico y esterilización 


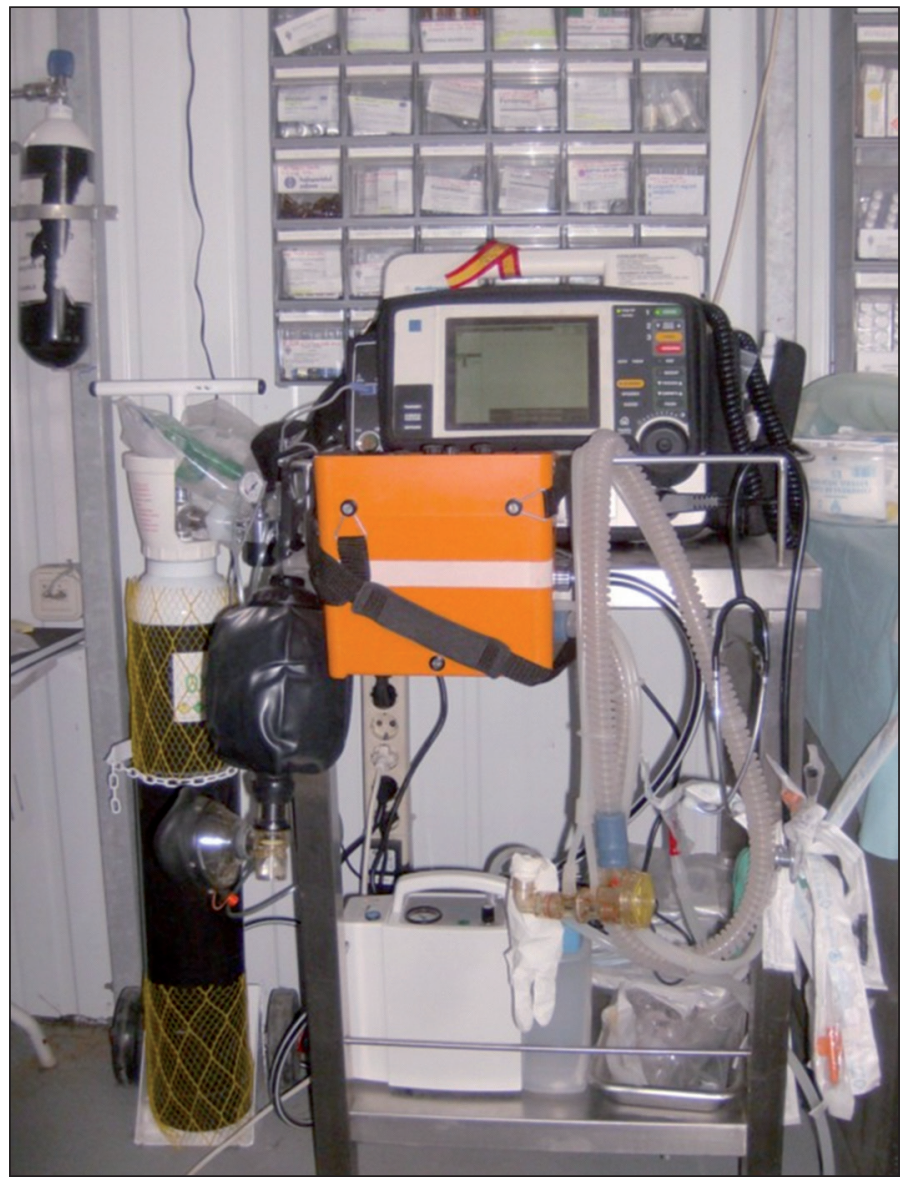

Figura 10. Área de SVA y Reanimación.

se valoran las características físicas y psicológicas del mismo, la presentación de un proyecto científico en el área de medicina, poseer conocimientos en las áreas de urgencias, medicina de montaña, odontología, telemedicina y electromedicina. Una vez designado, se encarga de diseñar la fase de preparación, control y adquisición del material farmacológico y médico, trabajo que es fundamental a la hora de realizar un tratamiento médico en una zona tan alejada de un centro hospitalario (1.000 kilómetros o 3 días de navegación).

Es importante resaltar que en la dotación de personal de la base no se cuenta con personal de enfermería, especialidad que, dado el aislamiento de la base, sería fundamental en el caso de tener que atender y evacuar a una baja con una patología grave.

\section{La enfermería de la base. Áreas}

La Base «Gabriel de Castilla» cuenta entre sus instalaciones con la enfermería «Capitán Médico Ramón y Cajal» con capacidad para realizar una asistencia sanitaria tipo atención primaria, así como de soporte vital básico y avanzado. Está alojada en un contenedor de 15 pies $\left(25 \mathrm{~m}^{2}\right)$, al que se le ha añadido un avance para evitar al máximo la pérdida de calor. El sistema eléctrico es autónomo por baterías, y ha sido potenciado durante el año 2009, con un sistema de placas solares, que le permite tener agua caliente, calefacción eléctrica, así como mantener los equipos de electromedicina conectados permanentemente.

La enfermería podemos dividirla funcionalmente en varias áreas o zonas:

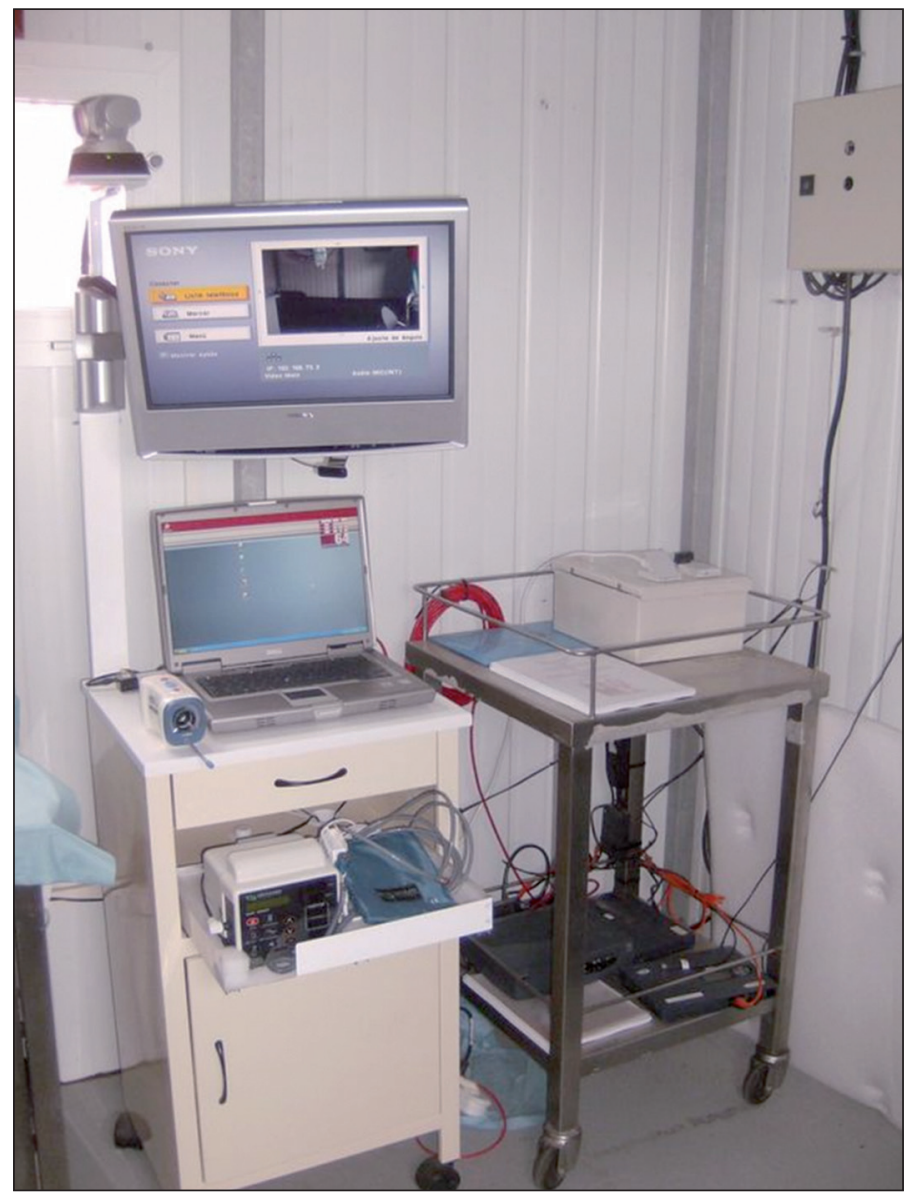

Figura 11. Equipo de telemedicina 2007-08.

\section{a) Zona de material de rescate y transporte sanitario}

Cuenta con el siguiente material:

- Camilla nido.

- Camilla UT 2000.

- Colchón de vacío.

- Camilla de palas.

- Inmovilizador cervical.

- Inmovilizador de columna tipo Kendrick.

- Férula de tracción.

- Férulas hinchables.

\section{b) Área de atención primaria y curas}

Hacemos referencia a la zona central de la enfermería donde se sitúa la camilla de exploración, así como diversos armarios de aluminio y compartimentos en la pared en los que se coloca el material sanitario y la medicación de uso para curas y enfermedades y contingencias comunes.

\section{c) Área de diagnóstico médico, electromedicina y esterilización}

Disponemos de una serie de material diagnóstico entre los que destacan los siguientes: 
- ECG Cardioline Delta 3 Plus.

- Analizador clínico portátil I-STAT.

- Monitor de constantes Propaq CS.

- Pulsioximetría Nonin.

- Autoclave Kavoklave II.

- Ecógrafo Sonosite 180.

\section{d) Área de soporte vital avanzado y reanimación}

Para la realización de las maniobras de soporte vital avanzado y reanimación, se cuenta con los siguientes elementos:

- Monitor-desfibrilador Life-Pack 12.

- Respirador Oxilog 2000.

- Aspirador de secreciones Atmos. Atmoport N.

- Mochilas SVA circulatorio y respiratorio.

El oxígeno es uno de los elementos que más problemas crea, tanto para su transporte como en caso de tener que reponer el mismo. La capacidad total de la base durante nuestra campaña era de 1 botella de 12 litros, 1 de 3 litros y 4 de 2 litros, esto hacía un total de 23 litros que a 200 BAR de presión hacían 4.600 litros. En caso de precisar 10 litros/minuto, hacen 460 minutos (7 horas y 40 minutos), período de tiempo algo escaso para poder evacuar a una víctima que precisara el mismo. Se podrría valorar la posibilidad de contar con una estación o planta generadora de oxígeno en la zona.

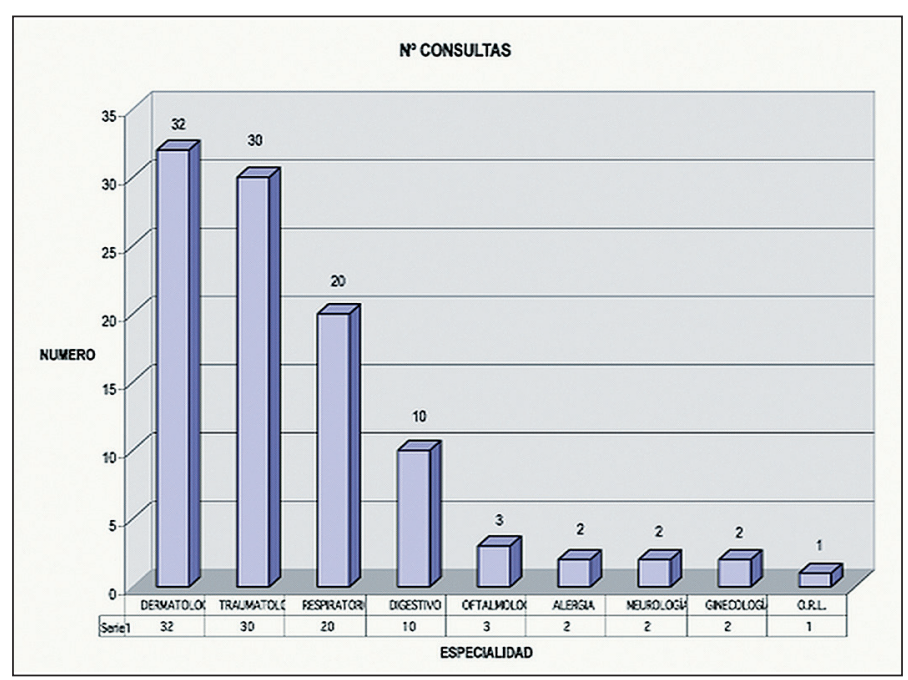

Figura 12. Número de atenciones 2007-08.

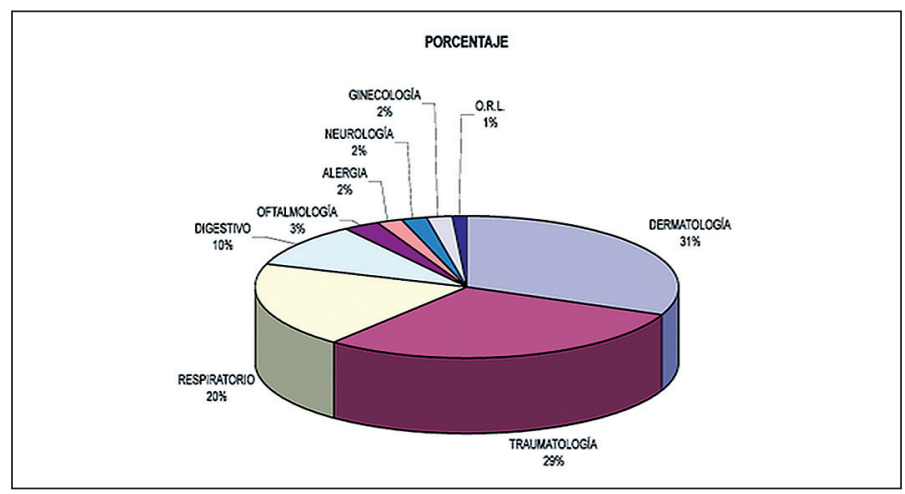

Figura 13. Atención médica en la XXII Campaña 2007-08.

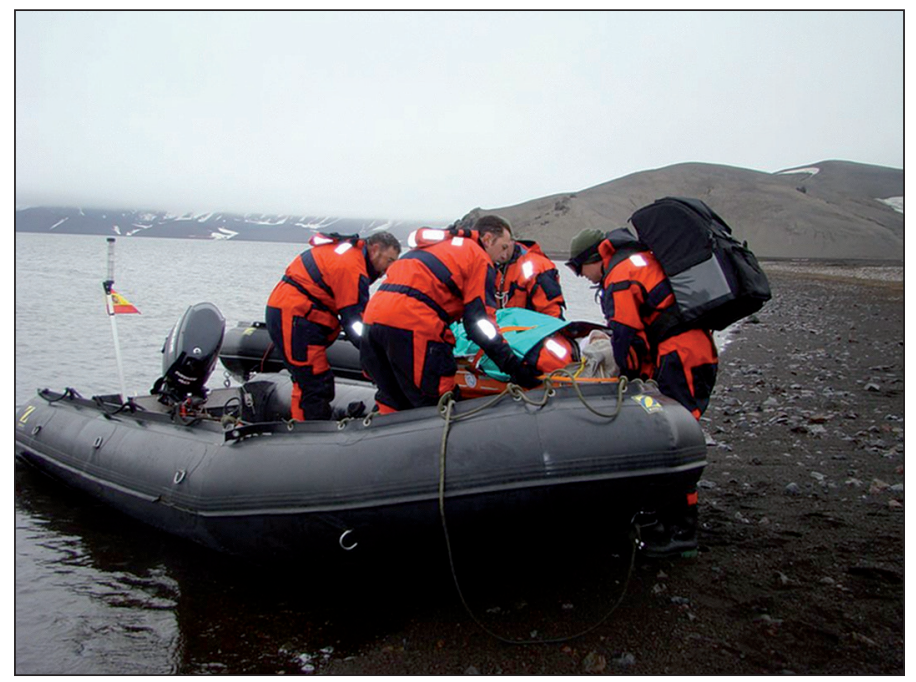

Figura 14. Embarcación tipo zodiac.

\section{e) Área de Telemedicina}

La Base Gabriel de Castilla, cuenta desde el año 2006 con un Equipo de Telemedicina, que se utiliza para la realización de consultas con el Servicio de Telemedicina del Hospital Central de la Defensa de Madrid. También se ha usado para comunicaciones con Presidencia de Gobierno, Ministerio de Defensa, la NASA (con el astronauta Pedro Duque, en la estación espacial internacional), el Aquarium de Valencia, conexiones con distintos medios de comunicación, colegios y otras instituciones públicas y privadas. Con dicho equipo se realizaban cada 15 días videoconferencias de control, en la que se comprobaba el funcionamiento de los distintos dispositivos de comunicación y diagnóstico, en especial, el ecógrafo (Sonosite 180), la cámara de alta resolución, el monitor de constantes vitales y el electrocardiógrafo. Actualmente está instalado dentro de cajones rugerizados que le confiere mayor protección.

El equipo consta de:

- Monitor Sony 19».

- Ordenador portátil DELL Latitude D810

- Cámara de alta resolución AMD 2500.

- ECG Welch Allyn. Cardio Perfect.

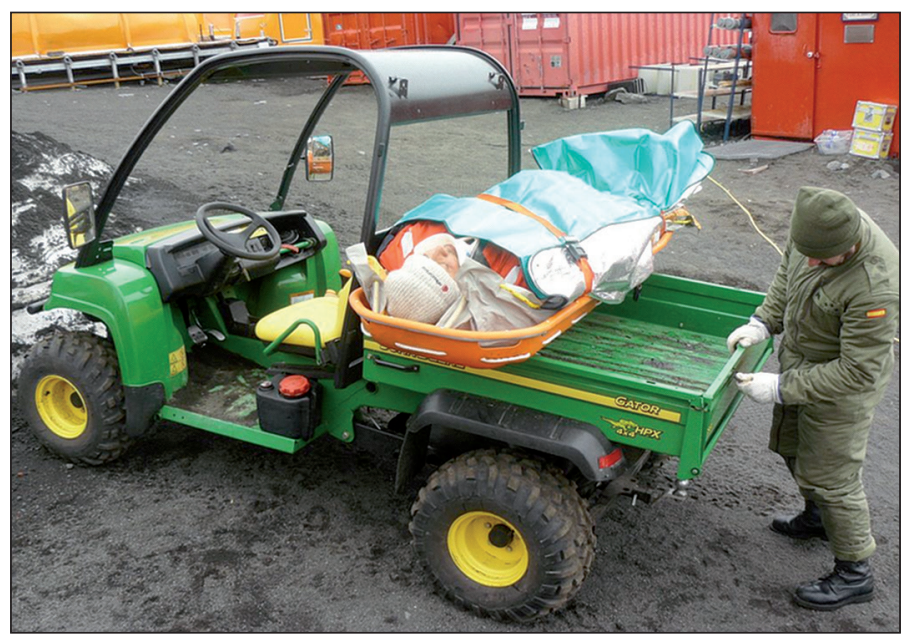

Figura 15. Vehículo John Deere Gator. 


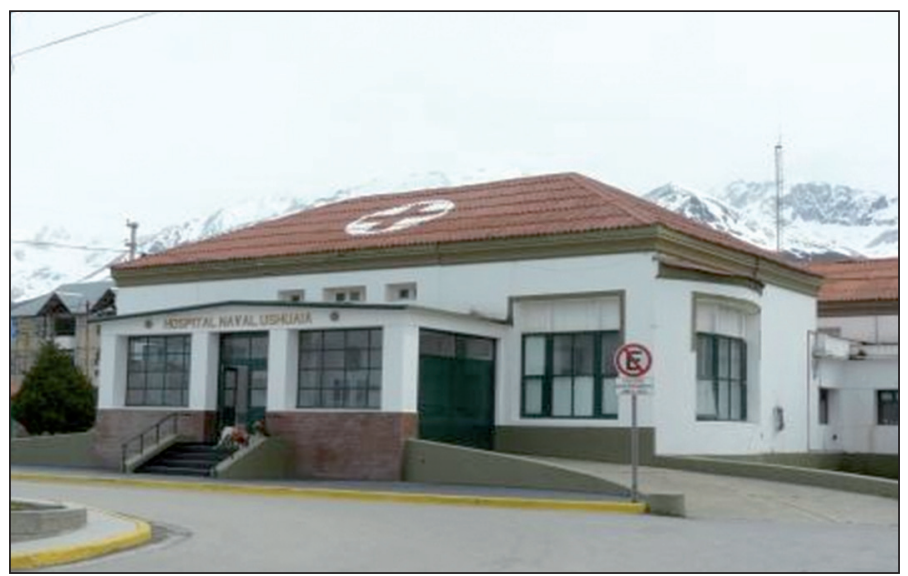

Figura 16. Hospital Regional de Ushuaia.

- Monitor de constantes Critcare 500DXNT.

- Cámara Sony.

- Micrófono inhalámbrico.

\section{f) Área de Farmacia y almacén}

La enfermería cuenta con un armario para el almacenaje de medicación y productos sanitarios.

\section{g) Área de observación, hospitalización y aislamiento}

En caso de enfermedad que precise observación, uso de distintos procedimientos diagnósticos, patología infecciosa, aislamiento o tratamiento continuado, la enfermería ofrece posibilidad de ingreso durante tiempo limitado.

Por la dotación de material de la enfermería se puede considerar que posee una capacidad tipo role 1, pero no podemos aceptarla como tal debido a la carencia de personal auxiliar y de enfermería.

Uno de los aspectos característicos de las campañas antárticas es la investigación y estudio de nuevos materiales y procedimientos en cada una de las áreas que la componen. En el área de medicina, se deben ir adquiriendo y probando, materiales y elementos nuevos, que puedan ayudar en el diagnóstico y tratamiento de las distintas patologías, y así, avanzar en el desarrollo de la medicina militar.

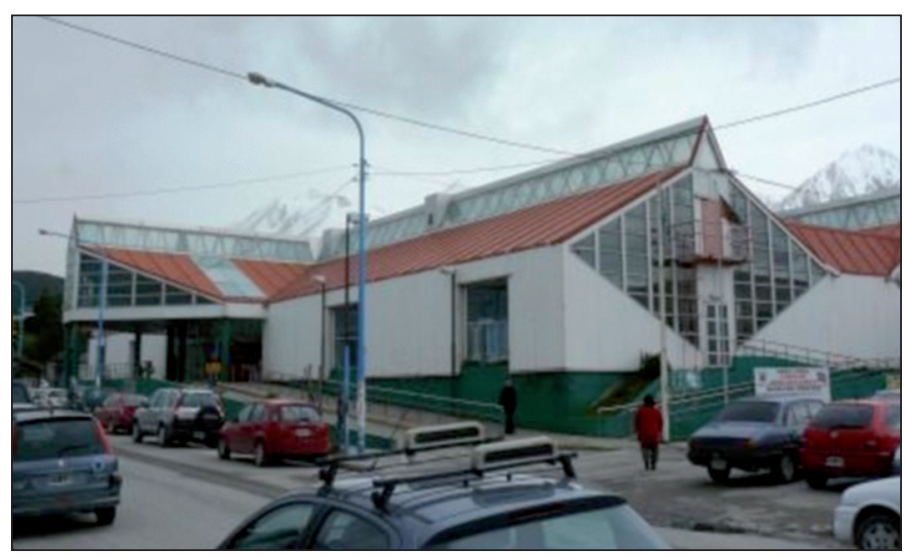

Figura 17. Hospital Naval de Ushuaia.
En ese sentido, sería muy interesante, incorporar un equipo de radiología digital, que aumentaría las capacidades diagnósticas y de tratamiento, sin descuidar el cuidado al medio ambiente.

\section{Capacidades médicas}

La disposición en la enfermería del material citado la dota con una serie de capacidades médicas entre las que destacamos la posibilidad diagnóstica (electrocardiograma de 12 derivaciones, monitorización de constantes vitales) y de tratamiento de procesos comunes. La realización de analíticas sanguíneas básicas con técnicas de test (hematocrito, hemoglobina, gases, electrolitos), la posibilidad de practicar ciertas intervenciones de cirugía menor, maniobras de soporte vital básico y avanzado. Posibilidad de conexión vía satélite con el Hospital Central de la Defensa a través del equipo de telemedicina, así como enviar imágenes ecográficas, entre otras pruebas. También se dispone de capacidad de dar tratamiento con oxigenoterapia y respiración asistida con respirador además de contar con medios adecuados para realizar una inmovilización y transporte de heridos con lesiones traumatológicas. También se practican y regulan las medidas de higiene y preventivas fundamentales para evitar la aparición de ciertas patologías transmisibles.

La actividad médica en la Base Gabriel de Castilla, tiene una serie de características que la hacen distinta al resto de misiones y lugares. Por ello el médico que acuda a la misma debería poseer una formación reglada para poder actuar por sí solo en caso de cualquier situación de urgencia. Esto incluiría formación en soporte vital avanzado con prácticas para la canalización de vías venosas, vía aérea y medicación de urgencia. Conocimiento y práctica en rescate en montaña, así como para realizar una evacuación o transporte sanitario por medio aéreo y marino. Saber utilizar e interpretar los distintos medios diagnósticos: ecografía básica, electrocardiografía, monitorización, analítica básica, telemedicina. La formación básica en odontología es importante debido al aislamiento, así como los conocimientos en medicina de montaña y lesiones por frío. Por

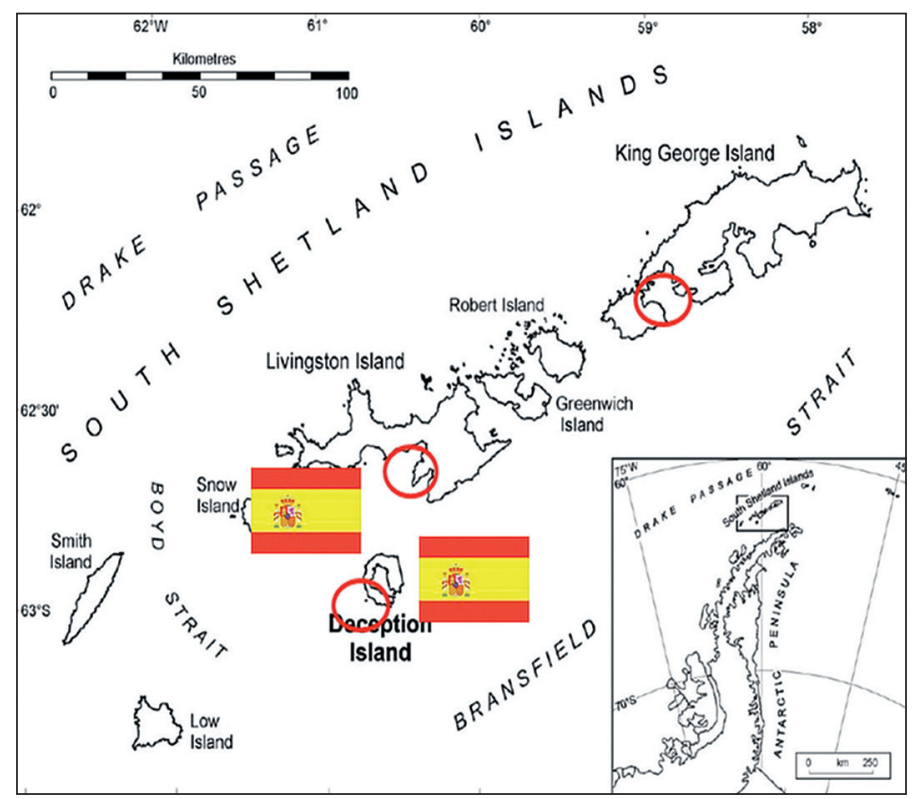

Figura 18. Mapa Islas Shetland del Sur. Bases «Gabriel de Castilla», «Juan Carlos I, Rey Frei. 
último y debido a las distintas actividades de buceo que se realizan en la isla es muy aconsejable poseer conocimientos en Medicina subacuática e hiperbárica.

\section{Atención médica}

Durante los 3 meses que estuvimos en la isla Decepción durante la Campaña 2007/08, se realizaron 102 consultas, la mayoría de ellas relacionadas con patología dermatológica y traumatológica.

- DERMATOLOGÍA:

32 CONS

- traumatología:

30 CONS

- RESPIRATORIO:

20 CONS

- DIGESTIVO:

10 CONS

- OFTALMOLOGÍA:

3 CONS

- NEUROLOGÍA:

2 CONS

- GINECOLOGÍA:

2 CONS

- ALERGIA:

2 CONS

- O.R.L.:

1 CONS

\section{Sistema de evacuacion de bajas}

La evacuación médica desde la Base «Gabriel de Castilla», hasta el centro hospitalario más cercano siempre ha sido uno de los retos más importantes dentro de la actividad médica en las distintas campañas. Por ello la realización de un Plan de Evacuación Médica, es fundamental para que, en caso de necesidad, se pueda realizar el traslado de la baja, una vez estabilizada.

En el Plan de Evacuación diferenciaremos entre la evacuación de una baja desde un punto de la isla hasta la enfermería de la base, para la que se disponen de medios terrestres (quads, vehículos todoterreno, camillas-trineo, camillas-nido) y medios acuáticos.

La evacuación realmente compleja sería la que se realizaría desde la base hasta un centro hospitalario en el continente o hasta la Base Frei, en la isla Rey Jorge, que dispone de aeropuerto y posibilidad de evacuación por vía aérea hasta Punta Arenas en Chile. Las

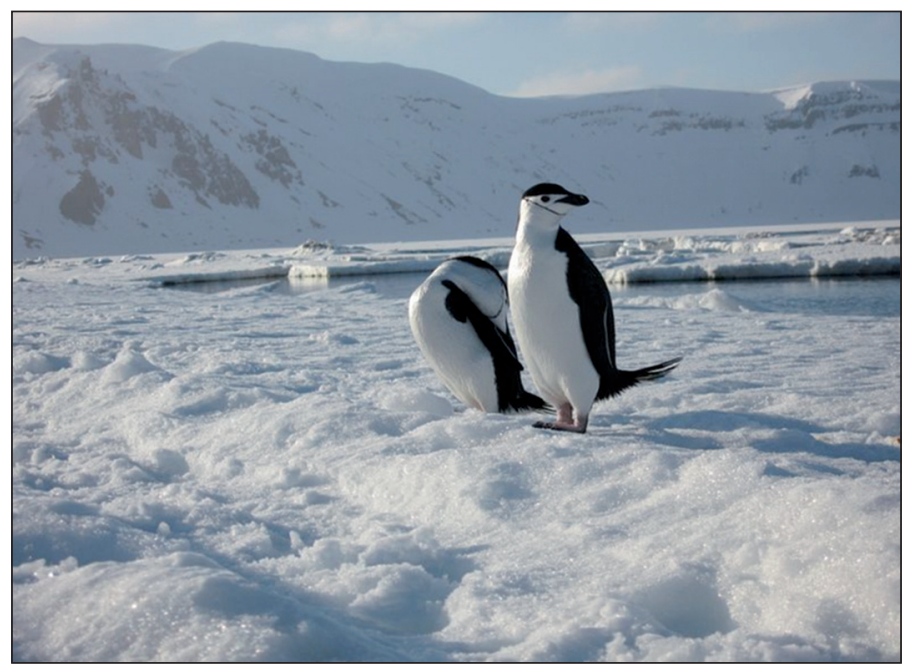

Figura 19. Pingüino barbijo (Pygoscelis antarctica).Su silueta forma parte del escudo de la Base Antártica Española Gabriel de Castilla. posibilidades de evacuación fuera de la isla, pasarían por la utilización de distintos medios, que en el caso de la Isla Decepción son:

\section{Vía marítima}

- Buque logístico BIO «Las Palmas»:

* Trayecto: Decepción-Ushuaia (Argentina): 72 horas.

* Trayecto: Decepción-Rey Jorge (Base Frei): 12 horas aprox.

- Buque oceanográfico BIO «Hespérides».

* Trayecto Decepción-Ushuaia (Argentina): 72 horas aprox.

* Trayecto Decepción-Rey Jorge (Base Frei): 8-10 horas aprox.

- Buques civiles y oceanográficos con/sin helicóptero que operen por la zona, con trayectos y tiempos semejantes a los anteriores.

\section{Vía aérea}

- Helicóptero Base Frei:

* Trayecto: Base Frei-Decepción y regreso: Unos 120 min, si hay buena meteorología.

- Avión: De Base Frei a Punta Arenas (Chile). 3 horas, con buena meteorología.

La ruta de evacuación más rápida y la que se valora como principal sería la vía aérea, teniendo la vía marítima como ruta alternativa, aunque en último caso dependería del tipo de patología, de la gravedad de las lesiones, la urgencia en la evacuación y la posibilidad de utilización del medio aéreo. El trayecto por vía aérea pasaría por evacuar a la baja a Base Frei en la Isla Rey Jorge y de allí al Hospital de Punta Arenas en Chile. Si el trayecto se realizara por vía maríti-

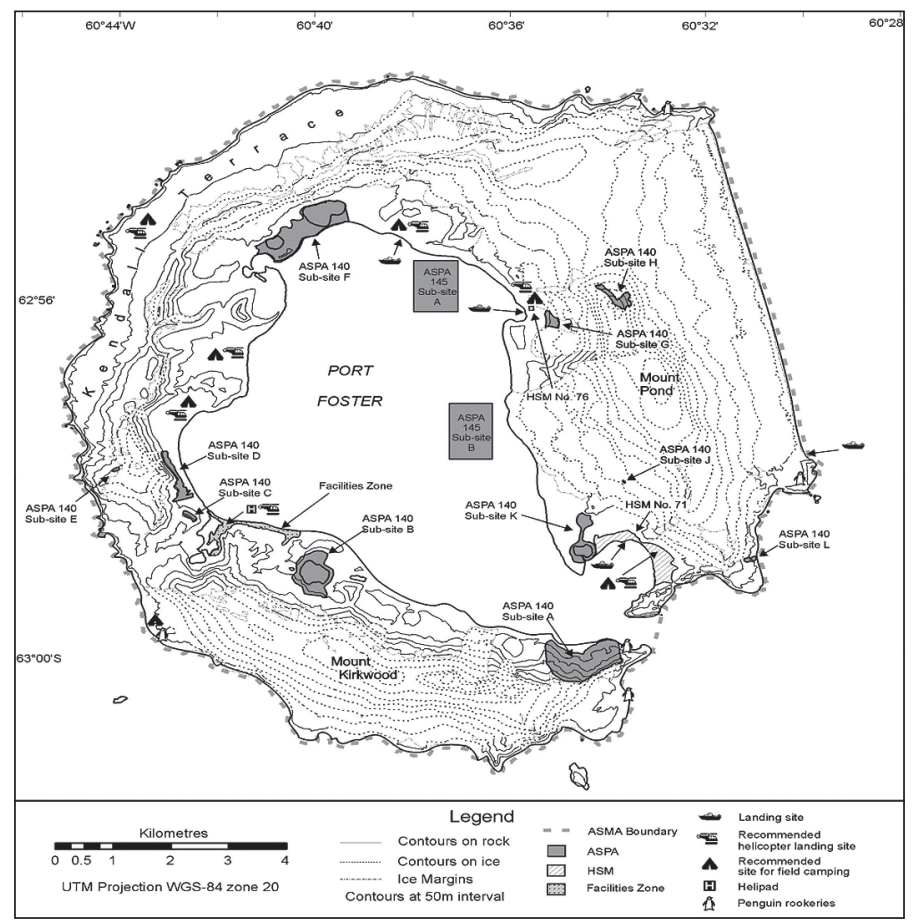

Figura 20. Zonas Antárticas Especialmente Protegidas en la Isla Decepción. 


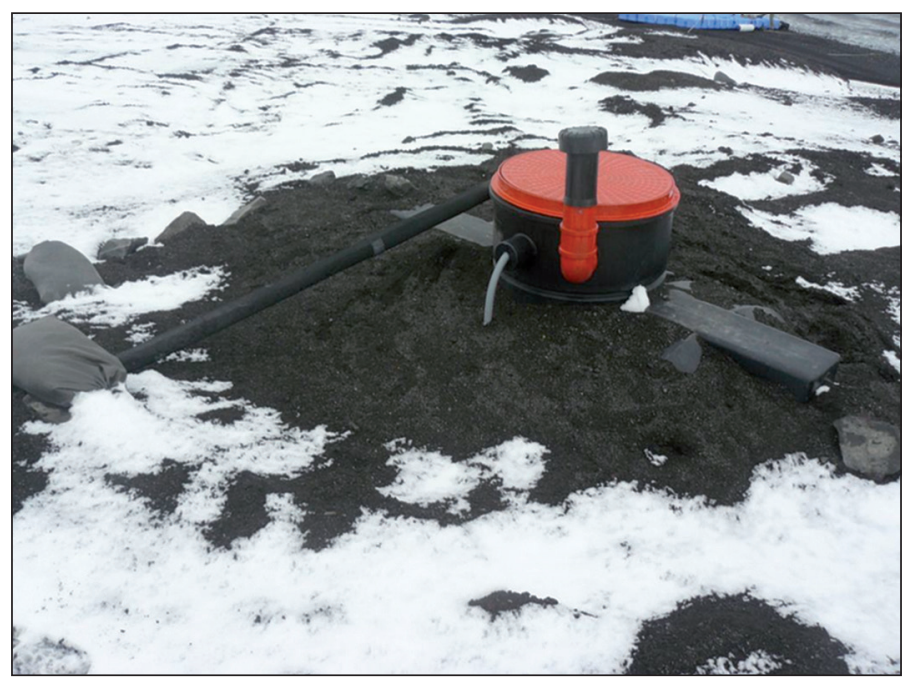

Figura 21. Reactor del sistema de depuración.

ma, se evacuaría al hospital regional de Ushuaia, o al hospital naval de Ushuaia si se trata de un caso de patología subacuática, al poseer un servicio de medicina subacuática con cámara hiperbárica.

El Comité Polar, en su función coordinadora de los distintos países, envía una serie de informes sobre las capacidades médicas de las distintas bases, para su utilización en caso de urgencia o emergencia. Las bases con capacidad sanitaria más cercanas a la isla Decepción son:

La Base argentina «Decepción» de la Armada Argentina data del año 1948 y está situada a unos 800 metros de la base Gabriel de Castilla. Entre sus instalaciones cuentan con una enfermería dirigida por un enfermero con material y medicación para realizar tratamientos y curas menores. Al estar tan cerca de nosotros hay una gran relación y apoyo entre ambas bases. Esta base suele abrir a mediados del mes de diciembre para cerrar a finales del mes de febrero.

A unos 80 kilómetros de la isla Decepción se encuentra la base Juan Carlos I, que posee una enfermería dirigida por un médico civil con el máster de medicina en montaña (061 Aragón), que le da una capacidad sanitaria semejante a la nuestra. Existe un proyecto de renovación de la base que mejoraría su habitabilidad.

La base chilena Frei, se encuentra en la Isla Rey Jorge, a unos 200 km, de isla Decepción. Entre sus instalaciones cuenta con una enfermería con personal médico y de enfermería y capacidad tipo role 1. Entre sus instalaciones hay un aeropuerto con aviones de ala fija y rotatoria.

La dificultad en la evacuación de bajas hace fundamental actualizar anualmente el plan de evacuación médica, sobre todo en el caso de tener que evacuar una persona con patología grave o que necesite tratamiento especializado urgente. Además precisaría que existiera en la zona un interlocutor o coordinador médico que regulara estos apoyos y tener un contacto permanente con el mismo.

Así mismo, en el I Foro Antártico celebrado en Zaragoza en octubre de 2009, se comentó la necesidad de sustituir el BIO Las Palmas, por otro buque con capacidad para embarcar un helicóptero que podría utilizarse, entre otros cometidos, para los casos de evacuación médica urgente.

Como anexos se adjuntan el formulario de declaración de las capacidades médicas de las bases y unidades (Anexo 1), el formulario de solicitud de MEDEVAC (Anexo 2), y la tabla con las capacidades médicas de bases y buques en zona antártica (Anexo 3).
ANEXO 1. CAPACIDADES MÉDICAS DE LAS BASESY UNIDADES.

Este informe se cumplimentara por las bases y unidades indicando la fecha de apertura y cierre, o bien las fechas que se prevé estar en zona antártica. Se enviará al Comité Polar, el cual realiza una tabla y las distribuye a las distintas bases y buques que operan en la Antártida.

\section{CAPACIDADES MÉDICAS DE LAS BASESY YNIDADES:}

UNIDAD QUE INFORMA DE SUS CAPACIDADES.

PARA: Coordinador médico Comité Polar

1. CIRUGIA (SURGERY)

2. LABORATORIO (LABORATORY)

3. RADIOLOGIA (RADIOLOGY)

4. BANCO DE SANGRE (BLOODBANK)

5. EQUIPO DE DENTISTA (DENTAL)

6. RESPIRADORES (RESPIRATORS)

7. DESFIBRILADORES (DEFIBRILLATORS)

8. N. ${ }^{\circ}$ DE CAMAS DISPONIBLES (AMOUNT OF BUNKS)

9. MEDICO (PHYSICIANS)

10. ENFERMERO (NURSE)

11. EXPERIENCIA/INTERES DEL MEDICO (EXPERIENCE/NTEREST OF PHYSICIANS)

12. DENTISTA (DENTISTS)

13. OTRO PERSONAL (OTHER PERSONNEL)

14. MED/DENT TECNICOS (MED/DENT TECHNICIANS)

15. HELICOPTERO (HELICOPTERS)

16. EMBARCACIONES (SHIP'S BOATS)

17. CAMILLAS* (STRETCHERS*)

18. OTROS DATOS DE INTERES:

- OTROS MEDIOS DE LOS QUE SE DISPONE:

- -CAPACIDAD DE APOYO DE MONTAÑA/ VIVAC.

- -CAPACIDAD REPOSTAJE HELO

- -CAPACIDAD DE VERTEX

- -CAPACIDAD ATERRIZAJE HELO

\section{- FORMA DE CONTACTAR CON ESTA UNIDAD:}

Telf Inmarsat:

Telf Nacional:

Frecuencia HF:

E-mail

* SE ESPECIFICARA POR SEPARADO EL N ${ }^{\circ}$ DE CAMILLAS DE AEROEVACUACION

\section{Campamentos temporales}

A lo largo de estos años, la actividad científica se ha desarrollado, tanto en la isla Livingston como en la isla Decepción, pero ha habido otros campamentos temporales, entre los que destacan los de la Península de Byers, situado en el extremo sur de la isla Livingston, y Caleta Cierva, que fue el primer campamento español en la península antártica del continente blanco. La actividad en esas zonas y el número limitado de personas en los mismos, hacían que contaran con medios de atención médica limitados, en forma de botiquines, y que los puntos de evacuación cambiaran a los de la isla Decepción.

\section{ÁREA DE MEDIO AMBIENTE}

El área de medio ambiente es responsabilidad de un Oficial del Cuerpo Militar de Sanidad, Especialidad Fundamental Veterinaria. 
ANEXO 2. SOLICITUD MEDEVAC.

$\left.1 .^{\circ}\right)$ Contacto con el coordinador médico. Solicitud.

$2^{\circ}$ ) En caso de no tener enlace con el coordinador, nos pondríamos en contacto con la base o unidad más cercana que disponga de dicho medio de evacuación.

3. $\left.{ }^{\circ}\right)$ En caso de no ser posible el punto . $^{\circ}$ 2, nos pondríamos en contacto con otra base para intentar el contacto a través de ella.

4. $\left.{ }^{\circ}\right)$ La información básica que necesitara el coordinador y el piloto de la aeronave será:

\section{MEDEVAC URGENTE}

Prioridad: INMEDIATA EN 12 HORAS EN 24 HORAS

DE: la unidad o base que solicita la evacuación (FM UNIT)

PARA: COORDINADOR MEDICO o Unidad que va a realizar la evacuación (TO COO)

MEDEVAC URGENTE N. ${ }^{\circ}$ FECHA HORA DE SOLICITUD

1. MEDEVAC REQUERIDA PARA:

A. PACIENTES EN CAMILLA, (N. ${ }^{\circ}$ DE PACIENTES)

B. PACIENTES SENTADOS, (N. ${ }^{\circ}$ DE PACIENTES)

C. CUIDADOS MEDICOS ESPECIALES (Oxigeno, fluidoterapia, etc....)

D. PERSONAL QUE DEBE ACOMPAÑAR AL PACIENTE

2. OBSERVACIONES DE INTERES

BT

\section{Sistema del Tratado Antártico}

En 1959 doce Naciones con intereses en el continente de hielo ratifican el Tratado Antártico, en el que se reconoce la importancia de las contribuciones aportadas al conocimiento científico por la investigación científica realizada en la Antártida por la Comunidad Internacional.

En años sucesivos, nuevas medidas entran en vigor para proteger el medio ambiente antártico y sus ecosistemas dependientes y asociados, constituyendo un conjunto de medidas e instrumentos internacionales que se denomina Sistema del Tratado Antártico.

En este Sistema sobresale el Protocolo del Tratado Antártico sobre Protección del Medio Ambiente de 1991. El también llamado Protocolo de Madrid (se firma en la capital de España) designa a la Antártida como reserva natural, consagrada a la paz y la ciencia.

España se adhiere al Tratado Antártico en 1982. Para dar cumplimiento a las disposiciones en el ámbito medioambiental contempladas en el Protocolo de Madrid que entran en vigor a partir de 1998, la Campaña Antártica incorpora en su estructura un Oficial Veterinario responsable del Área de Medio Ambiente.

\section{Protección medio ambiental de la Isla Decepción}

La isla Decepción, donde se localiza la Base Antártica Española "Gabriel de Castilla», es una isla de elevada riqueza en términos ambientales. Como ejemplo, decir que alberga una de las mayores poblaciones mundiales de pingüino barbijo (Pygoscelis antarctica).
En la Reunión Consultiva del Tratado Antártico celebrada en Estocolmo en 2005, se concede a la Isla Decepción la categoría de Zona Antártica Especialmente Administrada número 4.

Este reconocimiento se otorga por la singularidad en valores naturales, científicos, históricos, educacionales, estéticos, de flora y fauna de la isla, dotándola de un paquete de medidas de gestión.

Asimismo, en la isla Decepción se designan dos Zonas Antárticas Especialmente Protegidas (ZAEP) por su sobresaliente valor, la número 140, que incluye once sitios terrestres, y la número 145, que comprende dos hábitats bentónicos.

\section{Evaluación de impacto ambiental}

Previamente al inicio de la actividad en la base «Gabriel de Castilla», se remite al Comité Polar Español una evaluación previa del impacto ambiental de las actividades previstas a desarrollar en la Campaña, según contempla el Protocolo de Madrid (artículo 8, anexo I).

En la citada evaluación se describe la actividad propuesta incluyendo su objetivo, localización, duración e intensidad, así como los impactos acumulativos de las actividades anteriormente realizadas en pretéritas Campañas.

La consideración de nuestra actividad como de un impacto menor que mínimo o transitorio dará inicio a nuestra labor. De este modo, la actividad planificada se desarrolla dentro de los límites marcados por dicha evaluación.

\section{Sistema de gestión ambiental de la base antártica española Gabriel de Castilla}

El Sistema de Gestión Ambiental (SGA) responde a la voluntad de la Campaña Antártica de disponer de una herramienta que permita aplicar una Política Medioambiental, y cumplir con unos objetivos que lleven a una mejora continua de nuestro comportamiento ambiental en tierras antárticas.

El SGA se desarrolla en base a los siguientes documentos:

a) Manual de Gestión. De carácter general, incluye una presentación de la actividad y una declaración de intenciones representada por la Política Medioambiental. Define las responsabilidades entre los distintos componentes de la Campaña.

b) Procedimientos de Trabajo (PT,S). De carácter específico, expone el sistema de actuación para el control operacional, seguimiento y medición de la actividad que desarrollamos. Se describe un PT por cada actividad, producto o servicio que pueda interactuar con el medio ambiente, esto es, un PT para todos los aspectos ambientales que se identifican:

- Emisiones con incidencia en la atmósfera. Tienen su origen en los generadores, vehículos y motores fueraborda.

- Efluente de aguas residuales. Es sometido a proceso de depuración previo a su vertido, consistente en pretratamiento o decantación primaria y tratamiento biológico por lecho fijo.

- Residuos. Son segregados según su naturaleza y almacenados hasta su remoción fuera del Área del Tratado Antártico, según establece el Protocolo de Madrid (artículo 8; Anexo III).

- Ruido emitido al exterior. Su control permite evaluar su grado de incidencia sobre la fauna. 
La sanidad en la base antártica del E.T. «Gabriel de Castilla»

ANEXO 3. Capacidades médicas de distintas bases y buques en la antártida

\begin{tabular}{|c|c|c|c|c|c|c|c|c|c|c|c|}
\hline & $\begin{array}{l}\text { J. Carlos I } \\
\text { España }\end{array}$ & $\begin{array}{c}\text { Gabriel de } \\
\text { Castilla España }\end{array}$ & Bulgaria & $\begin{array}{c}\text { Decepción } \\
\text { (Argentina) }\end{array}$ & $\begin{array}{l}\text { Presidente } \\
\text { Frei. Chile }\end{array}$ & $\begin{array}{c}\text { Júbany } \\
\text { Argentina }\end{array}$ & $\begin{array}{c}\text { Base } \\
\text { Primavera } \\
\text { Argentina }\end{array}$ & $\begin{array}{l}\text { González } \\
\text { Videla. } \\
\text { Chile }\end{array}$ & $\begin{array}{l}\text { Oscar } \\
\text { Viel. } \\
\text { Buque } \\
\text { Armada } \\
\text { Chilena }\end{array}$ & $\begin{array}{c}\text { BIO } \\
\text { Hespérides } \\
\text { Barco } \\
\text { Armada } \\
\text { Española }\end{array}$ & $\begin{array}{c}\text { BIO Las } \\
\text { Palmas } \\
\text { Barco } \\
\text { Armada } \\
\text { Española }\end{array}$ \\
\hline Cirugía & MENOR & MENOR & MENOR & MENOR & MENOR & MENOR & MENOR & MENOR & MENOR & MENOR & MENOR \\
\hline Laboratorio & $\begin{array}{c}\text { Autoanalizador } \\
\text { bioquímica }\end{array}$ & BASICO & NO & NO & NO & BASICO & NO & NO & $?$ & BASICO & NO \\
\hline Radiología & NO & NO & NO & NO & SI & SI & NO & NO & DENTAL & SI & NO \\
\hline Odontología & NO & NO & NO & NO & SI & NO & NO & NO & SI & NO & NO \\
\hline B. Sangre & NO & NO & NO & NO & NO & NO & NO & NO & NO & NO & NO \\
\hline Respirador & SI & SI & NO & NO & SI & SI & $\begin{array}{c}\text { SOLO } \\
\text { OXIGENO }\end{array}$ & $\begin{array}{c}\text { SOLO } \\
\text { OXIGENO }\end{array}$ & $?$ & SI & SI \\
\hline Desfibrilador & SI & SI & NO & NO & SI & SI (2) & NO & NO & SI & SI & SI \\
\hline $\mathrm{N}^{\circ}$ Camas & 1 & 1 & $?$ & 1 & 2 & 1 & 1 & 1 & $?$ & $?$ & 20 CAMAS \\
\hline Médico & 1 & 1 & ALTERNA & NO & 1 & 1 & NO & NO & 1 & 1 & 1 \\
\hline Enfermero & NO & NO & ALTERNA & 1 & 1 & 1 & 1 & 1 & 1 & 1 & 1 \\
\hline Dentista & NO & NO & NO & NO & $\begin{array}{c}1 \text { MEDICO } \\
\text { CON } \\
\text { CONOC. }\end{array}$ & NO & NO & NO & 1 & NO & NO \\
\hline Otro personal & NO & VETERINARIO & NO & NO & NO & $\begin{array}{c}\text { Enfermero } \\
\text { Especialista } \\
\text { hiperbárica }\end{array}$ & NO & NO & NO & NO & NO \\
\hline Helicóptero & NO & NO & NO & NO & SI & NO & NO & NO & SI & NO & NO \\
\hline Helo Vertrep & SI & SI & SI & SI & SI & SI & SI & SI & SI & SI & NO \\
\hline $\begin{array}{c}\text { Zona } \\
\text { Aterrizaje }\end{array}$ & SI & SI & NO & SI & SI & SI & SI & SI & SI & $\begin{array}{c}\text { SI } \\
\text { Limitada }\end{array}$ & NO \\
\hline Helo Repostaje & NO & NO & NO & NO & SI & NO & NO & NO & SI & $?$ & NO \\
\hline Embarcaciones & 2 & 5 & NO & NO & $?$ & 2 & 1 & 1 & SI & 2 & 3 \\
\hline $\mathrm{N}^{\mathrm{o}}$ camillas & $?$ & 2 & $?$ & 1 & $?$ & 1 & 1 & 1 & 2 & 2 & 2 \\
\hline $\begin{array}{l}\text { Material } \\
\text { rescate }\end{array}$ & SI & SI & $?$ & $?$ & $?$ & $?$ & NO & NO & SI & SI & SI \\
\hline $\begin{array}{l}\text { Apoyo vivac/ } \\
\text { montaña }\end{array}$ & SI & SI & $?$ & ? & $?$ & ? & NO & NO & $?$ & $?$ & SI \\
\hline Otros medios & NO & $\begin{array}{l}\text { Telemedicina } \\
\text { Ecografía }\end{array}$ & NO & NO & $\begin{array}{l}\text { Telemedicina } \\
\text { Aeropuerto }\end{array}$ & $\begin{array}{l}\text { Cámara } \\
\text { Hiperbárica }\end{array}$ & NO & NO & $?$ & Telemedicina & NO \\
\hline Otros & & & $\begin{array}{l}\text { ona navegan } \\
\text { El buque } \\
\text { Cuenta con }\end{array}$ & $\begin{array}{l}\text { buques de dist } \\
\text { El BI } \\
\text { ARA Subofici } \\
\text { médico espec }\end{array}$ & $\begin{array}{l}\text { ntos países. Ent } \\
\text { Endurance (Gr } \\
\text { Castillo (Arge } \\
\text { alista en medici }\end{array}$ & $\begin{array}{l}\text { e ellos el buqu } \\
\text { an Bretaña) co } \\
\text { tina), apoya a } \\
\text { ta hiperbárica, }\end{array}$ & $\begin{array}{l}\text { Ary Rongel } \\
\text { helicóptero. } \\
\text { is bases arger } \\
\text { nfermero y c }\end{array}$ & $\begin{array}{l}\text { rasil), con } 2 \\
\text { nas de la zon } \\
\text { nara hiperbár }\end{array}$ & licópteros; & & \\
\hline
\end{tabular}

- Consumo de recursos energéticos y naturales. Hace referencia a combustibles fósiles y el recurso hídrico.

- Contaminación de suelos como consecuencia de un incidente. Se realiza un control de vigilancia en áreas sensibles y cuando se presenta un incidente para proceder a su minimización.

El control operacional, seguimiento y medición de los aspectos ambientales identificados permiten una respuesta en caso de que se produzca una desviación que pueda derivar en un impacto ambiental significativo. Igualmente, el registro generado en esta monitorización es objeto de interpretación, siendo esta información básica para la mejora del sistema.

Para la ejecución de estos PT,s, la Base Antárica Española Gabriel de Castilla está dotada del material necesario para proceder al control de los aspectos ambientales referidos, el cual es objeto de calibración y mejora en cada Campaña.
Cada nueva Campaña propone sus objetivos y metas medioambientales a desarrollar, lo cual se realiza en la Revisión en la que participa el Órgano Técnico de Apoyo a la Campaña Antártica en Medio Ambiente (SERVICIO DE VETERINARIA; AGRUSAN III (Agrupación de Sanidad); Zaragoza). Por citar un objetivo propuesto en la Campaña 2007/2008, hacer referencia a la instalación de un aerogenerador como compromiso de utilización de formas de energías renovables.

El SGA es un documento vivo, el cual se modifica en base a los resultados, interpretación y experiencia, así como de las auditorías de la que es objeto. Es el Órgano Técnico de Apoyo a la Campaña Antártica en Medio Ambiente el que custodia, asesora y da continuidad a esta herramienta entre los responsables del Área de Campaña en Campaña. 


\section{Planes de emergencia y capacidad de respuesta}

El SGA de Gabriel de Castilla contempla un capítulo particular para el procedimiento a seguir y responder a accidentes potenciales y situaciones de emergencia, así como para prevenir y reducir los impactos medioambientales que puedan estar asociados a ellos.

Los escenarios habituales de emergencia medioambiental que se barajan son los siguientes:

a) Emergencia sísmica.

b) Derrame de combustible.

c) Incendios.

Para afrontarlos, además del procedimiento, se dota a cada Campaña del material necesario.

\section{Formación, sensibilización y competencia profesional en materia medioambiental}

La formación, sensibilización y competencia profesional en materia medioambiental corresponde en su ejecución al responsable del Área de Medio Ambiente.

Sin duda, esta es la tarea más compleja del Área: que el personal integrante de la Campaña, así como el ajeno a la misma, que desarrolla su actividad en «Gabriel de Castilla», modifique o incorpore la pauta ambiental en su comportamiento dentro del Área del Tratado Antártico Comporta la interacción con cada individuo y sus valores éticos, lo cual comprende un compromiso personal por cada uno de los integrantes.

El SGA incluye el Manual de Conducta Medioambiental a divulgar entre los que participan de esta actividad. Resaltar a este respecto que en la Fase de Preparación de cada Campaña se incluye la formación del personal integrante en materia medio ambiental.

\section{PASADO, PRESENTE Y FUTURO DE LA CAMPAÑA ANTÁRTICA}

Desde el año 1989 en que se instaló la primera tienda y el primer refugio en la Isla Decepción han pasado por esta Base un gran número de personal científico y militar. Desde entonces han cambiado muchas cosas, empezando por las instalaciones, pasando por el material y los métodos utilizados para la investigación, la logística, los transportes, la gestión ambiental, etc. Coincidiendo con la celebración del Año Polar Internacional, entre el año 2007 y 2009, se ha llevado a cabo una ampliación del módulo de vida de la Base, aumentando la capacidad de alojamiento de personal científico y militar, añadiéndose otros módulos para ampliar su capacidad de almacenaje y logística.

El futuro de la misma en el área de Medicina pasa por la mejora continua que se produce en cada campaña, tanto a nivel de material como en los procedimientos diagnósticos y de evacuación, como en la formación específica en técnicas de urgencia y emergencia, telemedicina, ecografía, cirugía menor y odontología.

Con respecto al área de Medio Ambiente, destacar que en la Campaña 2009/2010 la Base Antártica Española Gabriel de Castilla ha sido objeto de una auditoría externa por parte de AENOR (Asociación Española de Normalización y Certificación), cuya evaluación ha resultado la certificación del Sistema de Gestión Ambiental según la norma ISO 14.001. El futuro de la Campaña Antártica queda supeditado al nivel de exigencia preciso para el mantenimiento de dicha certificación.

En definitiva, tras escuchar lo que la Antártida nos enseña a través de las pesquisas que desarrolla la investigación científica española, respondamos con un hacer en aquellas tierras en las que únicamente quede nuestro aprendizaje, con la mínima alteración posible de uno de los últimos grandes ecosistemas del planeta no alterados por la actividad humana.

\section{BIBLIOGRAFÍA}

1. Scientific Commitée on Antarctic Research. www.uam.es/otros/cn-scar/api.htm.

2. International Polar Year. www.ipy.org.

3. Informe final Campaña Antártica 2007-08. Medicina.

4. Comnap (Council of Managers of National Antarctic Programs). ATOM (Antarctic Telecommunications Operators Manual). http://www.comnap.aq/atom

5. Adhesión al Tratado Antártico de 1 de diciembre de 1959. B.O.E. núm. 152 de 26 de Junio de 1982.

6. Protocolo al Tratado Antártico sobre Protección del Medio Ambiente. XI Reunión Consultiva Especial del Tratado Antártico. Madrid, 1991.

7. Paquete de Medidas de Gestión de la Isla Decepción. XXVII Reunión Consultiva del Tratado Antártico. Estocolmo, 2005.

8. ISO 14001. Sistemas de Gestión Ambiental. Actualización de 2004

9. Sistema de Gestión Ambiental de la Base Antártica Española Gabriel de Castilla. EME. DIVOPE. 2004. 